\title{
Editorial
}

\section{Plastic concrete?}

\author{
C. J. Burgoyne \\ University of Cambridge
}

The idea that concrete is a plastic material, which can be studied using plasticity theory and the associated bound theorems, is not one that is easy to convey to each new generation of engineers. Plasticity theory, when taught, is usually associated with an idealised version of steel that is both linear elastic and perfectly plastic, and concrete is obviously a brittle material, which is neither of these things.

At the same time, finite element analyses are becoming very easy to use, and produce such pretty pictures, that it is easy to be seduced into the assumption that one knows the 'exact' value of the stresses everywhere in the structure. Experience shows that this is not true. In the rare cases where a structure is strain gauged, or where the deflections are monitored over time, they turn out not to be those predicted by elastic analysis. At the same time most of these structures have behaved perfectly well for years, with no signs of distress, even when the analysis predicts they should fail. The problem is that the accuracy of an exact analysis is illusory; assumptions have to be made about the support conditions, the exact material properties and the extent of cracking, which can never be known with certainty.

This does not mean that any structure which fails an elastic analysis is safe, nor does it mean that every structure designed using an elastic analysis will have to be redesigned. The reason that most engineers do not have to lie awake at night is the lower bound theorem, which all designers rely on but very few can quote. Most computer analysis techniques give a set of stresses that are in equilibrium with the applied loads, and if the designer makes the structure strong enough to resist these stresses, then the structure will be safe. There are of course caveats. The lower bound theorem relies on the structure having sufficient ductility to redistribute stresses within itself. Concrete as a material is brittle, but reinforced and prestressed concrete, when correctly detailed, are ductile. It must also be ensured that the structure does not suffer stability problems, but this is rarely a problem for chunky concrete sections.

The realisation that concrete could and should be designed using plastic methods led to the first major conference on the subject in 1979, held at the Technical University of Lyngby in Copenhagen under the auspices of The International Association for Bridge and Structural Engineering (IABSE) and the chairmanship of Professor Bruno Thurlimann. The ideas presented at that conference underpin all the modern design codes for concrete: Load Resistance Factor Design codes in the US, Limit State Codes elsewhere. The rules on shear design rely implicitly on plastic methods, even if this is not stated, and it is often forgotten in the sometimes heated debate about competing shear theories that they are simply alternative lower bounds to the same problem. The rules on analysis methods and allowable redistribution have at their heart the differences between elastic and plastic methods of analysis, and the ductility needed for the structure to move between the two states. Plasticity theory is still at the heart of virtually everything that is done by an engineer using concrete. The problems that are currently encountered when checking existing structures using finite elements, which were designed some time ago using simplified methods, could almost certainly be resolved if plastic methods were used to check them instead.

One of the young researchers at that conference in Copenhagen, and someone who has been at the heart of research into plastic theory applied to concrete ever 
since, was my colleague Dr Chris Morley of the University of Cambridge. He has recently retired, and to mark his retirement a symposium was held at Cambridge in July 2007. This special issue of the Magazine of Concrete Research carries the papers presented at that symposium that introduce new research or application of plasticity theory in the field of concrete structures.

The paper by Heyman reminds us that the key element in plasticity theory is the ability to determine an equilibrium set of forces, and for unreinforced concrete, as with masonry, the strength of the concrete is not usually an issue. The papers range through historical reviews, improvements in the analysis of slabs, improvements in shear design and some applications of plasticity theory to real-world problems. Taken together, these papers show why it is important that every generation of engineers should not just be able to apply modern code rules, but should also understand the basic mechanics that underlie them.

Discussion contributions on this paper should reach the editor by 1 April 2009 